\title{
Common Fixed Point Theorems on Weakly Contractive and Nonexpansive Mappings
}

\author{
Jian-Zhong Xiao and Xing-Hua Zhu \\ Department of Mathematics, Nanjing University of Information Science and Technology, \\ Nanjing 210044, China \\ Correspondence should be addressed to Jian-Zhong Xiao, xiaojz@nuist.edu.cn
}

Received 8 August 2007; Accepted 26 November 2007

Recommended by Jerzy Jezierski

A family of commuting nonexpansive self-mappings, one of which is weakly contractive, are studied. Some convergence theorems are established for the iterations of types Krasnoselski-Mann, Kirk, and Ishikawa to approximate a common fixed point. The error estimates of these iterations are also given.

Copyright (C) 2008 J.-Z. Xiao and X.-H. Zhu. This is an open access article distributed under the Creative Commons Attribution License, which permits unrestricted use, distribution, and reproduction in any medium, provided the original work is properly cited.

\section{Introduction and preliminaries}

Let $(X, d)$ be a metric space and $D \subset X$. A mapping $T: D \rightarrow X$ is said to be nonexpansive if

$$
d(T x, T y) \leq d(x, y), \quad \forall x, y \in D,
$$

and it is said to be weakly contractive if

$$
d(T x, T y) \leq d(x, y)-\psi(d(x, y)), \quad \forall x, y \in D,
$$

where $\psi:[0, \infty) \rightarrow[0, \infty)$ is continuous and nondecreasing such that $\psi$ is positive on $(0, \infty)$, $\psi(0)=0$, and $\lim _{t \rightarrow \infty} \psi(t)=\infty$.

It is evident that $T$ is contractive if it is weakly contractive with $\psi(t)=(1-\alpha) t$, where $\alpha \in(0,1)$, and it is nonexpansive if it is weakly contractive.

As an important extension of the class of contractive mappings, the class of weakly contractive mappings was introduced by Alber and Guerre-Delabriere [1]. In Hilbert and Banach spaces, Alber et al. [1-4] and Rhoades [5] established convergence theorems on iteration of fixed point for weakly contractive single mapping. 
Inspired by $[2,5,6]$, the purpose of this paper is to study a family of commuting nonexpansive mappings, one of which is weakly contractive, in arbitrary complete metric spaces and Banach spaces.

We will establish some convergence theorems for the iterations of types KrasnoselskiMann, Kirk, and Ishikawa to approximate a common fixed point and to give their error estimates.

Throughout this paper, we assume that $F(T)$ is the set of fixed points of a mapping $T$, that is, $F(T)=\{x: T x=x\}$; $\Phi$ is defined by the antiderivative (indefinite integral) of $1 / \psi(t)$ on $(0,+\infty)$, that is, $\Phi(t)=\int d t / \psi(t)$, and $\Phi^{-1}$ is the inverse function of $\Phi$.

We define iterations which will be needed in the sequel.

Suppose that $X$ is a metric space and $D \subset X,\left\{T_{r}\right\}_{r=0}^{k}$ is a family of commuting selfmappings of $D$ and $x_{0} \in D$. The iteration $\left\{x_{n}\right\}_{n=0}^{\infty} \subset D$ of type Krasnoselski-Mann (see [7, 8]) is cyclically defined by

$$
\begin{gathered}
x_{1}=T_{1} x_{0}, \ldots, \quad x_{k}=T_{k} x_{k-1}, \quad x_{k+1}=T_{0} x_{k}, \\
x_{k+2}=T_{1} x_{k+1}, \ldots, \quad x_{2(k+1)}=T_{0} x_{2 k+1}, \quad x_{2(k+1)+1}=T_{1} x_{2(k+1)}, \ldots
\end{gathered}
$$

For convenience, we write

$$
x_{n}=T_{n(\bmod k+1)} x_{n-1}
$$

where the $\bmod k+1$ function takes values in $\{0,1,2, \ldots, k\}$.

Let $D$ be a closed convex subset of the normed space $X$. Then the iteration $\left\{x_{n}\right\}_{n=0}^{\infty} \subset D$ of type Kirk (see $[5,9])$ is defined by

$$
x_{n}=S^{n} x_{0}, \quad n=1,2, \quad S=\sum_{i=0}^{k} a_{i} T_{i}, \quad a_{0}>0, \quad a_{i} \geq 0 \quad(i=1,2, \ldots, k), \quad \sum_{i=0}^{k} a_{i}=1 .
$$

Again, the iteration $\left\{x_{n}\right\}_{n=0}^{\infty} \subset D$ of type lshikawa with error (see [10-12]) is defined by

$$
\begin{gathered}
x_{n+1}=\left(1-a_{n 1}-b_{n 1}\right) x_{n}+a_{n 1} T_{1} y_{n 1}+b_{n 1} u_{n 1}, \\
y_{n 1}=\left(1-a_{n 2}-b_{n 2}\right) x_{n}+a_{n 2} T_{2} y_{n 2}+b_{n 2} u_{n 2}, \\
\vdots \\
y_{n(k-1)}=\left(1-a_{n k}-b_{n k}\right) x_{n}+a_{n k} T_{k} y_{n k}+b_{n k} u_{n k}, \\
y_{n k}=\left(1-a_{n 0}-b_{n 0}\right) x_{n}+a_{n 0} T_{0} x_{n}+b_{n 0} u_{n 0},
\end{gathered}
$$

where $\left\{u_{n i}\right\}_{n=0}^{\infty} \subset D(i=0,1, \ldots, k),\left\{a_{n i}\right\}_{n=0}^{\infty} \subset[0,1],\left\{b_{n i}\right\}_{n=0}^{\infty} \subset[0,1](i=0,1, \ldots, k)$, and

$$
\max _{0 \leq i \leq k}\left(a_{n i}+b_{n i}\right) \leq 1 \quad(n=0,1,2, \ldots) .
$$

We will make use of following result in theproof of Theorem 2.4. 
Lemma 1.1 (see [12]). Suppose that $\left\{\rho_{n}\right\},\left\{\sigma_{n}\right\}$ are two sequences of nonnegative numbers such that $\rho_{n+1} \leq \rho_{n}+\sigma_{n}$, for all $n \geq n_{0}$. If $\sum_{n=0}^{\infty} \sigma_{n}<\infty$, then $\lim _{n \rightarrow \infty} \rho_{n}$ exists.

\section{Main result}

Theorem 2.1. Let $(X, d)$ be a complete metric space and let $\left\{T_{r}\right\}_{r=0}^{k}$ be a family of commuting selfmappings, where $T_{i}(i=1,2, \ldots, k)$ are all nonexpansive and $T_{0}$ is weakly contractive, then there is a unique common fixed point $p \in \bigcap_{r=0}^{k} F\left(T_{r}\right)$ and the iteration $\left\{x_{n}\right\}$ of type Krasnoselski-Mann generated by (1.4) converges in metric to $p$, with the following error estimate:

$$
d\left(x_{n}, p\right) \leq \Phi^{-1}\left(\Phi\left(d\left(x_{0}, p\right)\right)-\left[\frac{n}{k+1}\right]\right) \quad(n=0,1,2, \ldots),
$$

where $[n /(k+1)]$ is the Gauss integer of $n /(k+1)$.

Proof. The uniqueness of fixed point of $T_{0}$ is clear from (1.2). Hence, the common fixed point of $\left\{T_{r}\right\}_{r=0}^{k}$ is unique. Let $X_{0}$ be an arbitrary point in $X$ and let $\left\{x_{n}\right\}$ be an iteration of type Krasnoselski-Mann generated by (1.4). Since $\left\{T_{r}\right\}_{r=0}^{k}$ is commutative, then we have $\prod_{r=0}^{k} T_{r}=$ $\left(\prod_{r=1}^{k} T_{r}\right) T_{0}$. Suppose that $n=i(\bmod k+1)$ and $[n /(k+1)]=j$. Then,

$$
x_{n}=x_{j(k+1)+i}=\left(\prod_{r=0}^{k} T_{r}\right) x_{(j-1)(k+1)+i} \quad(i=0,1,2, \ldots, k, j=1,2, \ldots) .
$$

Write $y_{j}=x_{j(k+1)+i}$ for fixed $i$. Then $\left\{y_{j}\right\}_{j=0}^{\infty}$ is a subsequence of $\left\{x_{n}\right\}$. Since $\prod_{r=1}^{k} T_{r}$ is nonexpansive and $T_{0}$ is weakly contractive, then we obtain

$$
\begin{aligned}
d\left(y_{j+1}, y_{j}\right) & =d\left(\left(\prod_{r=1}^{k} T_{r}\right) T_{0} y_{j},\left(\prod_{r=1}^{k} T_{r}\right) T_{0} y_{j-1}\right) \\
& \leq d\left(T_{0} y_{j}, T_{0} y_{j-1}\right) \leq d\left(y_{j}, y_{j-1}\right)-\psi\left(d\left(y_{j}, y_{j-1}\right)\right),
\end{aligned}
$$

which shows $d\left(y_{j+1}, y_{j}\right) \leq d\left(y_{j}, y_{j-1}\right)$, that is, $\left\{d\left(y_{j+1}, y_{j}\right)\right\}_{j=0}^{\infty}$ is a nonincreasing sequence of nonnegative real numbers. Therefore, it tends to a limit $d \geq 0$. If $d>0$, then, by nondecreasity of $\psi, \psi\left(d\left(y_{j+1}, y_{j}\right)\right) \geq \psi(d)$, for all $j \geq 0$. Thus, from (2.3) it follows that

$$
d\left(y_{j+k+1}, y_{j+k}\right) \leq d\left(y_{j+1}, y_{j}\right)-k \psi(d),
$$

a contradiction for $k$ large enough. Therefore,

$$
\lim _{j \rightarrow \infty} d\left(y_{j+1}, y_{j}\right)=0
$$

By (2.5), for any given $\varepsilon>0$, there exists $N$ such that

$$
d\left(y_{j+1}, y_{j}\right)<\min \left\{\frac{\varepsilon}{2}, \psi\left(\frac{\varepsilon}{2}\right)\right\}, \quad \forall j \geq N .
$$

We claim that

$$
d\left(y_{j+m}, y_{j}\right)<\varepsilon, \quad \forall m \geq 1, \forall j \geq N
$$


In fact, from (2.6) we see that (2.7) holds when $m=1$. Suppose that $d\left(y_{j+m-1}, y_{j}\right)<\varepsilon$. If $d\left(y_{j+m-1}, y_{j}\right)<\varepsilon / 2$, then from (2.6) we get

$$
d\left(y_{j+m}, y_{j}\right) \leq d\left(y_{j+m}, y_{j+m-1}\right)+d\left(y_{j+m-1}, y_{j}\right)<\frac{\varepsilon}{2}+\frac{\varepsilon}{2}=\varepsilon .
$$

If $d\left(y_{j+m-1}, y_{j}\right) \geq \varepsilon / 2$, then $\psi\left(d\left(y_{j+m-1}, y_{j}\right)\right) \geq \psi(\varepsilon / 2)$, we also get

$$
\begin{aligned}
d\left(y_{j+m}, y_{j}\right) & \leq d\left(y_{j+m}, y_{j+1}\right)+d\left(y_{j+1}, y_{j}\right) \\
& =d\left(\left(\prod_{r=0}^{k} T_{r}\right) y_{j+m-1},\left(\prod_{r=0}^{k} T_{r}\right) y_{j}\right)+d\left(y_{j+1}, y_{j}\right) \\
& \leq d\left(y_{j+m-1}, y_{j}\right)-\psi\left(d\left(y_{j+m-1}, y_{j}\right)\right)+d\left(y_{j+1}, y_{j}\right) \\
& <\varepsilon-\psi\left(\frac{\varepsilon}{2}\right)+\psi\left(\frac{\varepsilon}{2}\right)=\varepsilon .
\end{aligned}
$$

Therefore, by induction we derive that (2.7) holds. Since $\varepsilon$ is arbitrary, $\left\{y_{j}\right\}$ is a Cauchy sequence. As $X$ is complete, we have

$$
\lim _{j \rightarrow \infty} x_{j(k+1)+i}=p_{i} \in X \quad(i=0,1,2, \ldots, k) .
$$

Observe that $T_{i}(i=0,1,2, \ldots, k)$ are all continuous, so is $\prod_{r=0}^{k} T_{r}$. From $(2.10)$, it follows that

$$
\begin{gathered}
\left(\prod_{r=0}^{k} T_{r}\right) p_{i}=\lim _{j \rightarrow \infty}\left(\prod_{r=0}^{k} T_{r}\right) x_{j(k+1)+i}=\lim _{j \rightarrow \infty} x_{(j+1)(k+1)+i}=p_{i} \quad(i=0,1,2, \ldots, k), \\
T_{i+1} p_{i}=\lim _{j \rightarrow \infty} T_{i+1} x_{j(k+1)+i}=\lim _{j \rightarrow \infty} x_{j(k+1)+(i+1)=p_{i+1}} \quad\left(i=0,1,2, \ldots, k ; T_{k+1}=T_{0} ; p_{k+1}=p_{0}\right)
\end{gathered}
$$

By (1.1), (1.2), and (2.11), we deduce

$$
\begin{aligned}
d\left(p_{s}, p_{t}\right) & =d\left(\left(\prod_{r=0}^{k} T_{r}\right) p_{s},\left(\prod_{r=0}^{k} T_{r}\right) p_{t}\right) \\
& \leq d\left(p_{s}, p_{t}\right)-\psi\left(d\left(p_{s}, p_{t}\right)\right), \quad \forall t \neq s \in\{0,1,2, \ldots, k\},
\end{aligned}
$$

which shows

$$
p_{s}=p_{t}, \quad \text { that is, } p_{i}=p \quad(i=0,1,2, \ldots, k) .
$$

From (2.12), it implies that $p$ is a common fixed point of $\left\{T_{r}\right\}_{r=0}^{k}$, that is, $p \in \bigcap_{r=0}^{k} F\left(T_{r}\right)$. Hence, $\bigcap_{r=0}^{k} F\left(T_{r}\right)=\{p\}$. By (2.10) and (2.14), we conclude $\lim _{n \rightarrow \infty} x_{n}=p$. Set $\alpha_{j}=d\left(x_{j(k+1)}, p\right)$. From (2.3), we have

$$
\alpha_{j} \leq \alpha_{j-1}-\psi\left(\alpha_{j-1}\right), \quad \forall j \in Z^{+} .
$$

Since $\psi$ is continuous and nondecreasing, using (2.15), it yields

$$
\begin{gathered}
\Phi\left(\alpha_{j-1}\right)-\Phi\left(\alpha_{j}\right)=\int_{\alpha_{j}}^{\alpha_{j-1}} \frac{d t}{\psi(t)} \geq \frac{\alpha_{j}-\alpha_{j-1}}{\psi\left(\alpha_{j-1}\right)} \geq 1, \\
\alpha_{j} \leq \Phi^{-1}\left(\Phi\left(\alpha_{0}\right)-j\right) .
\end{gathered}
$$


Observe that

$$
\begin{aligned}
d\left(x_{n}, p\right) & =d\left(x_{j(k+1)+i}, p\right)=d\left(T_{i} \cdots T_{2} T_{1} x_{j(k+1)}, T_{i} \cdots T_{2} T_{1} p\right) \\
& \leq d\left(x_{j(k+1)}, p\right), \quad 1 \leq i \leq k .
\end{aligned}
$$

From (2.16) and (2.17), we obtain the error estimate (2.1). This completes the proof.

Remark 2.2. If $T_{i}=I(i=1,2, \ldots, k)$ in Theorem 2.1, where $I$ is the identity mapping of $X$, then we conclude that the sequence $\left\{x_{n}\right\}$ converges to the unique common fixed point $p$ of weakly contractive mapping $T_{0}$, with the error estimate $d\left(x_{n}, p\right) \leq \Phi^{-1}\left(\Phi\left(d\left(x_{0}, p\right)-n\right)\right)$, where $x_{n}=T_{0}^{n} x_{0}$. Thus, our Theorem 2.1 is a generalization of the corresponding theorem of Rhoades [5].

Theorem 2.3. Let $X$ be a Banach space and let $D \subset X$ be a nonempty closed convex set. Let $\left\{T_{r}\right\}_{r=0}^{k}$ be a family of commuting self-mappings, where $T_{i}: D \rightarrow D,(i=1,2, \ldots, k)$ are all nonexpansive and $T_{0}: D \rightarrow D$ is weakly contractive. Then, for any $x_{0} \in X$, the iteration $\left\{x_{n}\right\}$ of type Kirk generated by (1.5) converges strongly to a unique common fixed point $p \in \bigcap_{i=0}^{k} F\left(T_{r}\right)$, with the following error estimate:

$$
\left\|x_{n+1}-p\right\| \leq a_{0} \Phi^{-1}\left[\frac{1}{a_{0}} \Phi\left(\sum_{i=0}^{k} a_{i}\left\|T_{i} x_{0}-p\right\|\right)-n\right] \quad(n=1,2, \ldots) .
$$

Proof. Applying Theorem 2.1, we can suppose that $p$ is a unique common fixed point of $\left\{T_{r}\right\}_{r=0}^{k}$. Since

$$
S p=\left(\sum_{i=0}^{k} a_{i} T_{i}\right) p=\sum_{i=0}^{k} a_{i}\left(T_{i} p\right)=\sum_{i=0}^{k} a_{i} p=p,
$$

we derive that $p$ is a fixed point of $S$. Since $T_{i}(i=1,2, \ldots, k)$ are all nonexpansive, $T_{0}$ is weakly contractive, and $a_{0} \neq 0$, then we have

$$
\begin{aligned}
\|S x-S y\| & =\left\|\sum_{i=0}^{k} a_{i}\left(T_{i} x-T_{i} y\right)\right\| \leq \sum_{i=0}^{k} a_{i}\left\|T_{i} x-T_{i} y\right\| \\
& \leq a_{0}\|x-y\|-a_{0} \psi(\|x-y\|)+\sum_{i=1}^{k} a_{i}\|x-y\| \\
& =\|x-y\|-a_{0} \psi(\|x-y\|) .
\end{aligned}
$$

The inequality (2.20) shows that $S$ is weakly contractive. Thus, $p$ is a unique fixed point of $S$. Set $\psi_{1}=a_{0} \psi$. Then,

$$
\Phi_{1}=\frac{1}{a_{0}} \Phi, \quad \Phi_{1}^{-1}=a_{0} \Phi^{-1},
$$

and $\left\{x_{n}\right\}$ converges to $p$ with the following error estimate (see Remark 2.2):

$$
\left\|x_{n+1}-p\right\| \leq \Phi_{1}^{-1}\left[\Phi_{1}\left(\left\|x_{1}-p\right\|\right)-n\right] \text {. }
$$

Observe that

$$
\left\|x_{1}-p\right\|=\left\|S x_{0}-p\right\| \leq \sum_{i=0}^{k} a_{i}\left\|T_{i} x_{0}-p\right\| .
$$

From (2.21)-(2.23), we obtain (2.18). This completes the proof. 
Theorem 2.4. Let $X$ be a Banach space and let $D \subset X$ be a nonempty closed convex set. Let $\left\{T_{r}\right\}_{r=0}^{k}$ be a family of commuting self-mappings, where $T_{i}: D \rightarrow D(i=1,2, \ldots, k)$ are all nonexpansive and $T_{0}: D \rightarrow D$ is weakly contractive. For any $x_{0} \in D$, let $\left\{x_{n}\right\}$ be the iteration of type Ishikawa generated by (1.6), where

$$
\sum_{n=0}^{\infty} \prod_{i=0}^{k} a_{n i}=\infty, \quad \sum_{n=0}^{\infty} \max _{0 \leq i \leq k} b_{n i}<\infty,
$$

and $\left\{u_{n i}\right\}_{n=0}^{\infty} \subset X(i=0,1, \ldots, k)$ are all bounded. Then, $\left\{x_{n}\right\}$ converges strongly to a unique common fixed point $p \in \bigcap_{r=0}^{s} F\left(T_{r}\right)$ with the following estimate:

$$
\left\|x_{n+1}-p\right\| \leq \Phi^{-1}\left(\Phi\left(\left\|x_{0}-p\right\|\right)-\sum_{j=0}^{n} \prod_{i=0}^{k} a_{j i}\right)+M \sum_{j=0}^{n} \sum_{i=0}^{k} b_{j i},
$$

where $M=\max _{0 \leq i \leq k} \sup _{n \geq 1}\left\|u_{n i}-p\right\|$.

Proof. Applying Theorem 2.1, we can suppose that $p$ is a unique common fixed point of $\left\{T_{r}\right\}_{r=0}^{k}$. Since $\left\{u_{n i}\right\}(i=0,1, \ldots, k)$ are all bounded, we have $M=\max _{0 \leq i \leq k}$ $\sup _{n \geq 1}\left\|u_{n i}-p\right\|<\infty$. Since $T_{i}(i=1,2, \ldots, k)$ are all nonexpansive and $T_{0}$ is weakly contractive, we obtain in proper order that

$$
\begin{aligned}
\left\|y_{n k}-p\right\| \leq & \left(1-a_{n 0}-b_{n 0}\right)\left\|x_{n}-p\right\|+a_{n 0}\left\|T_{0} x_{n}-p\right\|+b_{n 0}\left\|u_{n 0}-p\right\| \\
\leq & \left(1-a_{n 0}\right)\left\|x_{n}-p\right\|+a_{n 0}\left[\left\|x_{n}-p\right\|-\psi\left(\left\|x_{n}-p\right\|\right)\right]+b_{n 0} M \\
\leq & \left\|x_{n}-p\right\|-a_{n 0} \psi\left(\left\|x_{n}-p\right\|\right)+b_{n 0} M, \\
\left\|y_{n(k-1)}-p\right\| \leq & \left(1-a_{n k}-b_{n k}\right)\left\|x_{n}-p\right\|+a_{n k}\left\|T_{k} y_{n k}-p\right\|+b_{n k}\left\|u_{n k}-p\right\| \\
\leq & \left(1-a_{n k}\right)\left\|x_{n}-p\right\|+a_{n k}\left\|y_{n k}-p\right\|+b_{n k} M \\
\leq & \left(1-a_{n k}\right)\left\|x_{n}-p\right\|+a_{n k}\left[\left\|x_{n}-p\right\|-a_{n 0} \psi\left(\left\|x_{n}-p\right\|\right)+b_{n 0} M\right]+b_{n k} M \\
\leq & \left\|x_{n}-p\right\|-a_{n 0} a_{n k} \psi\left(\left\|x_{n}-p\right\|\right)+\left(b_{n 0}+b_{n k}\right) M, \\
\left\|y_{n 1}-p\right\| \leq & \quad\left\|x_{n}-p\right\|-a_{n 0}\left(\prod_{i=2}^{k} a_{n i}\right) \psi\left(\left\|x_{n}-p\right\|\right)+\left(b_{n 0}+\sum_{i=2}^{k} b_{n i}\right) M, \\
\left\|x_{n+1}-p\right\| \leq & \left(1-a_{n 1}-b_{n 1}\right)\left\|x_{n}-p\right\|+a_{n 1}\left\|T_{1} y_{n 1}-p\right\|+b_{n 1}\left\|u_{n 1}-p\right\| \\
\leq & \left(1-a_{n 1}\right)\left\|x_{n}-p\right\|+a_{n 1}\left\|y_{n 1}-p\right\|+b_{n 1} M \\
\leq & \left(1-a_{n 1}\right)\left\|x_{n}-p\right\|+b_{n 1} M \\
& +a_{n 1}\left[\left\|x_{n}-p\right\|-a_{n 0}\left(\prod_{i=2}^{k} a_{n i}\right) \psi\left(\left\|x_{n}-p\right\|\right)+\left(b_{n 0}+\sum_{i=2}^{k} b_{n i}\right) M\right] \\
\leq & \left\|x_{n}-p\right\|-\left(\prod_{i=0}^{k} a_{n i}\right) \psi\left(\left\|x_{n}-p\right\|\right)+M \sum_{i=0}^{k} b_{n i} .
\end{aligned}
$$

Write $\beta_{n}=\left\|x_{n}-p\right\|, \theta_{n}=M \sum_{i=0}^{k} b_{n i}$. Then $\sum_{n=0}^{\infty} \theta_{n}<\infty$, and (2.26) yields

$$
\begin{gathered}
\beta_{n+1} \leq \beta_{n}+\theta_{n} \\
\sum_{j=0}^{n} \prod_{i=0}^{k} a_{j i} \psi\left(\beta_{j}\right) \leq \sum_{j=0}^{n}\left(\beta_{j}-\beta_{j+1}\right)+\sum_{j=0}^{n} \theta_{j} \leq \beta_{0}+\sum_{j=0}^{n} \theta_{j} .
\end{gathered}
$$


From (2.27) and Lemma 1.1, it implies that $\lim _{n \rightarrow \infty} \beta_{n}$ exists, and so does $\lim _{n \rightarrow \infty} \psi\left(\beta_{n}\right)$ by the continuity of $\psi$. From (2.28), it implies that $\sum_{n=0}^{\infty}\left(\prod_{i=0}^{k} a_{n i}\right) \psi\left(\beta_{n}\right)<\infty$. Since $\sum_{n=0}^{\infty}\left(\prod_{i=0}^{k} a_{n i}\right)=\infty$, we conclude that $\lim _{n \rightarrow \infty} \psi\left(\beta_{n}\right)=0$. Therefore, $\lim _{n \rightarrow \infty} \beta_{n}=0$, that is, $x_{n}$ converges strongly to $p$. To establish the error estimate, we set $\sum_{j=0}^{n} \theta_{j}=\Gamma_{n}$ and $\Gamma_{-1}=0$. Then, (2.26) yields

$$
\beta_{n+1} \leq \beta_{n}-\left(\prod_{i=0}^{k} a_{n i}\right) \psi\left(\beta_{n}\right)+\Gamma_{n}-\Gamma_{n-1}
$$

Set $\lambda_{n}=\beta_{n}-\Gamma_{n-1}$. From (2.29) we have

$$
\lambda_{n+1} \leq \lambda_{n}-\left(\prod_{i=0}^{k} a_{n i}\right) \psi\left(\lambda_{n}+\Gamma_{n-1}\right)
$$

Since $\psi$ is nondecreasing, from (2.30) we deduce

$$
\Phi\left(\lambda_{n}\right)-\Phi\left(\lambda_{n+1}\right)=\int_{\lambda_{n+1}}^{\lambda_{n}} \frac{d t}{\psi(t)} \geq \frac{\lambda_{n}-\lambda_{n+1}}{\psi\left(\lambda_{n}\right)} \geq \frac{\lambda_{n}-\lambda_{n+1}}{\psi\left(\lambda_{n}+\Gamma_{n-1}\right)} \geq \prod_{i=0}^{k} a_{n i}
$$

Thus,

$$
\begin{gathered}
\Phi\left(\lambda_{0}\right)-\Phi\left(\lambda_{n+1}\right)=\sum_{j=0}^{n}\left[\Phi\left(\lambda_{j}\right)-\Phi\left(\lambda_{j+1}\right)\right] \geq \sum_{j=0}^{n} \prod_{i=0}^{k} a_{j i} \\
\lambda_{n+1} \leq \Phi^{-1}\left(\Phi\left(\lambda_{0}\right)-\sum_{j=0}^{n} \prod_{i=0}^{k} a_{j i}\right) .
\end{gathered}
$$

Hence, the estimate (2.25) holds. This completes the proof.

\section{Acknowledgment}

This work is supported by the National Natural Science Foundation of China (10671094).

\section{References}

[1] Y. I. Alber and S. Guerre-Delabriere, "Principle of weakly contractive maps in Hilbert spaces," in New Results in Operator Theory and Its Applications, vol. 98 of Operator Theory: Advances and Applications, pp. 7-22, Birkhäuser, Basel, Switzerland, 1997.

[2] Y. I. Alber, C. E. Chidume, and A. Zegeye, "Approximating fixed points of total asymptotically nonexpansive mappings," Fixed Point Theory and Applications, vol. 2006, Article ID 10673, 20 pages, 2006.

[3] Y. I. Alber and S. Guerre-Delabriere, "On the projection methods for fixed point problems," Analysis, vol. 21, no. 1, pp. 17-39, 2001.

[4] Y. I. Alber, S. Guerre-Delabriere, and L. Zelenko, "The principle of weakly contractive mappings in metric spaces," Communications on Applied Nonlinear Analysis, vol. 5, no. 1, pp. 45-68, 1998.

[5] B. E. Rhoades, "Some theorems on weakly contractive maps," Nonlinear Analysis: Theory, Methods and Applications, vol. 47, no. 4, pp. 2683-2693, 2001.

[6] N. Hussain and A. R. Khan, "Common fixed-point results in best approximation theory," Applied Mathematics Letters, vol. 16, no. 4, pp. 575-580, 2003. 
[7] H. H. Bauschke, "The approximation of fixed points of compositions of nonexpansive mappings in Hilbert space," Journal of Mathematical Analysis and Applications, vol. 202, no. 1, pp. 150-159, 1996.

[8] J. Borwein, S. Reich, and I. Shafrir, "Krasnoselski-Mann iterations in normed spaces," Canadian Mathematical Bulletin, vol. 35, no. 1, pp. 21-28, 1992.

[9] W. A. Kirk, "On successive approximations for nonexpansive mappings in Banach spaces," Glasgow Mathematical Journal, vol. 12, pp. 6-9, 1971.

[10] S. Ishikawa, "Fixed points by a new iteration method," Proceedings of the American Mathematical Society, vol. 44, no. 1, pp. 147-150, 1974.

[11] S. Ishikawa, "Fixed points and iteration of a nonexpansive mapping in a Banach space," Proceedings of the American Mathematical Society, vol. 59, no. 1, pp. 65-71, 1976.

[12] K. K. Tan and H. K. Xu, "Approximating fixed points of nonexpansive mappings by the Ishikawa iteration process," Journal of Mathematical Analysis and Applications, vol. 178, no. 2, pp. 301-308, 1993. 